\title{
Fluorometric and Docking Analysis of the Complex Formation between an Anti-cancer Drug, Chlorambucil and Bovine Serum Albumin
}

\author{
Aimi Nabila Mohamad Saufi', Nor Farrah Wahidah Ridzwan², Saharuddin Bin Mohamad ${ }^{2,3}$, \\ Saad Tayyab ${ }^{1,3}$, Adyani Azizah Abd Halim ${ }^{4 *}$
}

1Biomolecular Research Group, Biochemistry Programme, Institute of Biological Sciences, Faculty of Science, University of Malaya, Kuala Lumpur, MALAYSIA.

${ }^{2}$ Bioinformatics Programme, Institute of Biological Sciences, Faculty of Science, University of Malaya, Kuala Lumpur, MALAYSIA. ${ }^{3}$ Centre of Research for Computational Sciences and Informatics for Biology, Bioindustry, Environment, Agriculture and Healthcare, University of Malaya, Kuala Lumpur, MALAYSIA.

${ }^{4}$ Department of Oral and Craniofacial Sciences, Faculty of Dentistry, University of Malaya, Kuala Lumpur, MALAYSIA.

\begin{abstract}
Background: To characterize the interaction between chlorambucil ( $\mathrm{CHB}$ ) and the carrier protein, bovine serum albumin (BSA) in order to understand the transport of this drug in blood circulation. Methods: Fluorescence quenching titration method was used to examine the interaction of $\mathrm{CHB}$ with BSA by determining its binding constant and binding stoichiometry. The binding site identification was probed with molecular docking techniques. Results: Values of the Stern-Volmer constant $\left(K_{S V}\right)$, bimolecular quenching rate constant $\left(k_{q}\right)$ and binding constant $\left(K_{a}\right)$ for CHB-BSA system were determined as $3.57 \times 10^{4} \mathrm{M}^{-1}, 5.67 \times 10^{12} \mathrm{M}^{-1} \mathrm{~s}^{-1}$ and $5.58 \times 10^{4} \mathrm{M}^{-1}$, respectively. Binding stoichiometry was found to be $\sim 1.0$, as obtained from the double logarithmic plot. The molecular docking results revealed that CHB binds to both Site I and Site II of BSA, however Site II was predicted to be the preferred binding site. Conclusion: The value of $K_{a}$ suggested intermediate binding affinity between $\mathrm{CHB}$ and BSA with the binding stoichiometry of $1: 1$. CHB was found to have the binding preference at Site II of BSA due to formation of greater contacts.
\end{abstract}

Key words: Bovine serum albumin, Chlorambucil, Drug-protein interaction, Fluorescence quenching, Molecular docking.

\section{INTRODUCTION}

Chlorambucil (CHB) (Figure 1) is an FDAapproved anticancer agent, which is used to treat chronic lymphocytic leukemia and some other types of cancers like Hodgkin's and Non-Hodgkin's lymphoma. ${ }^{1}$ Pharmacokinetic and pharmacodynamic properties of a drug are affected by several factors such as its transport in the blood circulation, bioavailability, distribution and metabolism, which depend on its association with plasma proteins. ${ }^{2,3}$ Improvement of the drug solubility, efficacy and half-life in plasma are also influenced by its binding to the plasma proteins. Therefore, molecular action of these drugs in human body can be well understood by studying the drug binding to the carrier proteins. ${ }^{48}$

The major carrier protein in blood circulation is serum albumin. ${ }^{9}$ Bovine serum albumin (BSA) has been widely selected as a prototype for drug binding research due to its availability, low cost and being homologous (76\% homologous sequences) to human serum albumin. ${ }^{9-12}$ BSA consists of 583 amino acid residues in a single chain with a molecular mass of $66430 \mathrm{Da}$. It is assemble of domains I, II and III, which are homologous to each other and are comprised of two sub-domains, A and B. ${ }^{9-12}$ Subdomains IIA and IIIA house the
Submission Date: 04-03-2019; Revision Date: 26-04-2019; Accepted Date: 26-07-2019

DOI: 10.5530/ijper.53.4.131 Correspondence: Dr. Adyani Azizah Abd Halim,

Department of Oral and Craniofacial Sciences, Faculty of Dentistry, University of Malaya- 50603, Kuala Lumpur, MALAYSIA. Phone: +603 79677405 E-mail: adyaniazizah@ um.edu.my

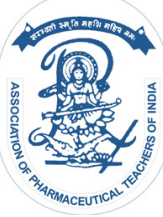

www.ijper.org 


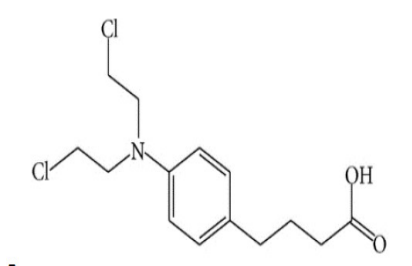

A.

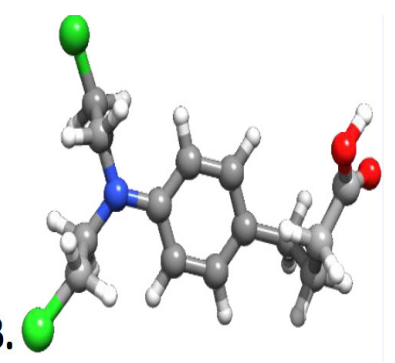

Figure 1: Structural representations of CHB. (A) Chemical structure and $(B)$ ball-and-stick model.

well-characterized ligand binding sites i.e. Sudlow's sites I and II, respectively. ${ }^{9-12}$ Due to the absence of any published report on the transport of $\mathrm{CHB}$ in blood circulation, it is valuable to get insight about the CHB-BSA binding mechanism by determining the binding affinity and binding stoichiometry along with binding site identification. Fluorescence spectroscopy and molecular docking approaches were employed to characterize CHB-BSA interaction.

\section{MATERIALS AND METHODS}

\section{Materials}

Bovine serum albumin (BSA), Fraction V, essentially $\gamma$-globulin free (Lot 087K0675) was supplied by SigmaAldrich Inc., St. Louis, MO, USA. Chlorambucil (CHB) was purchased from Selleck Chemicals, USA. Analytical grade samples of other chemicals were used. The deionized water was secured from Milli- $Q^{\circledR}$ Integral Water Purification System for Ultrapure Water (Merck KGaA, Darmstadt, Germany).

\section{Analytical Procedures}

A constant volume of sodium phosphate buffer ( $60 \mathrm{mM}, \mathrm{pH} 7.0$ ) was added to the desired amount of BSA to make the protein stock solution $(30 \mu \mathrm{M})$. The actual concentration of the prepared protein stock solution was determined using the specific extinction coefficient of 6.67 at $279 \mathrm{~nm} .{ }^{13}$ The drug stock solution was made by dissolving $5 \mathrm{mg}$ of $\mathrm{CHB}$ in $5 \mathrm{~mL}$ of dimethylsulfoxide (DMSO). The working CHB solution $(100 \mu \mathrm{M})$ was made from the stock solution by diluting it with the same buffer to be used in titration experiment. DMSO concentration in all experiments was $<1 \%$.

\section{Fluorescence Spectroscopy}

The fluorescence spectra of BSA $(3 \mu \mathrm{M})$ were attained in the wavelength range, $300-400 \mathrm{~nm}$ after exciting the protein sample at $295 \mathrm{~nm}$ on a Jasco FP-6500 spectrofluorometer. Various parameters were fixed as: excitation and emission slits - $10 \mathrm{~nm}$ each, data pitch - $1 \mathrm{~nm}$, scan speed $-300 \mathrm{~nm} \mathrm{~min}{ }^{-1}$ and response time - $0.08 \mathrm{~s}$.

\section{CHB-BSA Interaction Studies}

The fluorescence quenching titration method was employed to study the binding of $\mathrm{CHB}$ to BSA. ${ }^{7}$ Increasing $\mathrm{CHB}$ concentrations in the range of $0-18 \mu \mathrm{M}$ with $3 \mu \mathrm{M}$ intervals were added to a fixed concentration $(3 \mu \mathrm{M})$ of BSA solution in the total volume of $3.0 \mathrm{~mL}$. After incubating the mixture for $1 \mathrm{~h}$ at $25^{\circ} \mathrm{C}$ for equilibrium establishment, fluorescence spectra were recorded.

The fluorescence spectra were amended due to inner filter effect contribution with the help of the following equation $^{14}$

$$
\mathrm{F}_{c o r}=\mathrm{F}_{o b s} 10\left(\frac{\text { Aex }+ \text { Aem }}{2}\right)
$$

The corrected fluorescence intensity values at $344 \mathrm{~nm}$ were then changed to relative fluorescence intensity following the published procedure. ${ }^{7}$

\section{Fluorescence Data Analysis}

The Stern-Volmer quenching constant $\left(K_{S V}\right)$ of CHB-BSA system was determined with the help of the following equation:

$$
\frac{\mathrm{F}_{0}}{\mathrm{~F}}=1+K_{s v}[\mathrm{Q}]=1+k_{q} \tau_{0}[\mathrm{Q}]
$$

where each term has its usual meaning. ${ }^{14}$ Value of the bimolecular quenching rate constant $\left(k_{q}\right)$ was obtained by dividing the $K_{s v}$ value with $\tau_{o}$, the biomolecule's (BSA) average lifetime in the absence of any quencher $\left(6.3 \times 10^{-9} \mathrm{~s}\right) .^{15}$

Values of the binding constant, $K_{a}$ and the binding stoichiometry, $n$ of CHB-BSA interaction were acquired after fitting the data according to double logarithmic equation ${ }^{16}$

$$
\log \frac{\left(\mathrm{F}_{0}-\mathrm{F}\right)}{\mathrm{F}}=\log K_{a}+n \log [\mathrm{Q}]
$$

Free energy change value, $\Delta G^{\circ}$ for CHB-BSA interaction was quantified after substitution of the values of $R$ $\left(8.314 \mathrm{~J} \mathrm{~mol}^{-1} \mathrm{~K}^{-1}\right)$ and $T\left(=273+{ }^{\circ} \mathrm{C}\right)$ in the following equation $^{17}$

$$
\Delta G^{\circ}=-R T \ln K_{a}
$$

\section{Molecular Docking}

The docking of $\mathrm{CHB}$ to BSA was executed with AutoDock 4 by employing the Lamarckian genetic algorithm search engine. ${ }^{18}$ The three-dimensional (3D) 
structure of $\mathrm{CHB}$ was built and optimized with the MMF94 force field ${ }^{19}$ using Avogadro software. ${ }^{20}$ Crystallized structure of BSA was obtained from the Protein Data Bank (PDB) with the resolution of $2.47 \AA$ (PDB ID: 4F5S). Preparation steps for the BSA structure included the deletion of crystallized water, addition of polar hydrogens and computing its Kollman charges by AutoDockTools $4^{18}$ prior to the docking simulation. Gasteiger charges were applied on CHB and its rotatable bond was defined as part of its preparation. Independent docking simulation for the two main drug binding sites on BSA, namely subdomain IIA (Site I) and subdomain IIIA (Site II) was conducted by specifying each of their grid coordinates. The grid box dimension was $70 \times 70 \times 70$ points with a spacing of $0.375 \AA$ and was centred at: $\mathrm{x}=-4.49, \mathrm{y}=32.71, \mathrm{z}=100.41$ for Site $\mathrm{I}$ and $\mathrm{x}=10.04$, $y=18.22, z=122.13$ for Site II, separately. The docking simulation search run was set to 100 , with a population size of 150 with 27,000 generations and 250,000 energy evaluations for both docking procedures. Furthermore, the operator weights for crossover, mutation and elitism were set at 0.8, 0.02 and 1, respectively. Assessment of the docking results was performed by clustering them based on the root-mean-squared deviation (RMSD) tolerance of $2.0 \AA$ and the generated interactions were visualised and captured using UCSF Chimera. ${ }^{21}$ In addition, LigPlot+analysis was also performed to investigate the interaction between $\mathrm{CHB}$ and the binding sites I and II of BSA.22

\section{RESULTS AND DISCUSSION}

\section{Fluorescence Data Analysis of CHB-BSA System}

Drug-protein interactions have been widely investigated using fluorescence spectroscopy. Trp residues of the protein (BSA) are excited at $295 \mathrm{~nm}$ and contribute to its intrinsic fluorescence spectrum. ${ }^{23}$ Variation of the protein's fluorescence spectrum may reflect changes in protein conformation, denaturation, ligand binding or association of subunits. ${ }^{24}$ The addition of a drug to BSA generally leads to the quenching of its intrinsic fluorescence spectrum, which can be caused by several molecular interactions, such as the formation of ground state complex, molecular rearrangements, energy transfer, excited-state reactions and collisional quenching. ${ }^{25}$ Figure 2 depicts the BSA fluorescence spectra for both with and without $\mathrm{CHB}$ at increasing concentrations in the wavelength range, $300-400 \mathrm{~nm}$. BSA's fluorescence spectrum showed an emission maximum at $344 \mathrm{~nm}$ due to $\operatorname{Trp}$ residues in the protein molecules. The fluorescence intensity gradually reduced upon $\mathrm{CHB}$ addition. About $39 \%$ reduction in the fluorescence intensity (Figure 2

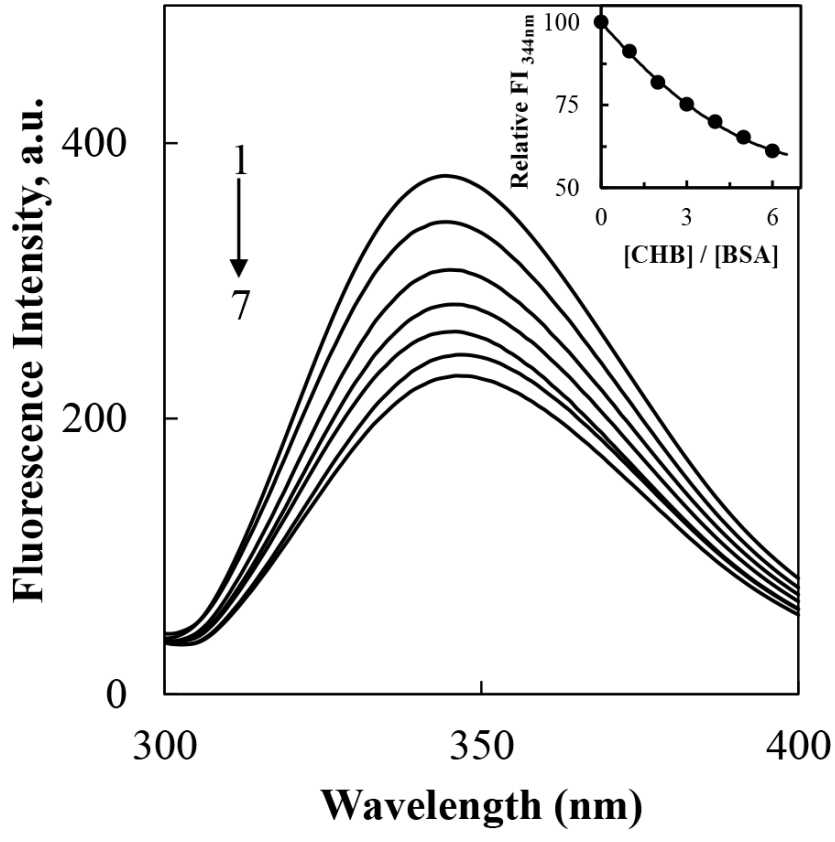

Figure 2: Spectra showing fluorescence quenching titration results of BSA $(3 \mu \mathrm{M})$ with increasing CHB concentrations upon excitation at $295 \mathrm{~nm}$, as studied in $60 \mathrm{mM}$ sodium phosphate buffer, $\mathrm{pH} 7.0$ at $25^{\circ} \mathrm{C}$. Spectrum 1 shows the fluorescence spectrum of BSA whereas spectra 2-7 were obtained upon addition of $3,6,9,12,15$ and $18 \mu \mathrm{M}$ CHB, respectively. Decrease in the relative fluorescence intensity of BSA at $344 \mathrm{~nm}$ (Relative $\mathrm{FI}_{344 \mathrm{~nm}}$ ) with increasing CHB concentrations is shown in the inset.

inset) along with $4 \mathrm{~nm}$ red shift were evident in the presence of $18 \mu \mathrm{M}$ CHB. The reduction in the fluorescence intensity of BSA after addition of $\mathrm{CHB}$ might be resulted due to microenvironmental alteration (reduced hydrophobicity) around Trp residues of BSA (Trp-134 and Trp-213). Similar fluorescence properties of BSA have been reported earlier upon drug binding., ${ }^{4,16,26}$

The fluorescence data were treated with the Stern-Volmer equation (2) and the results are depicted in Figure 3A. A linear Stern-Volmer plot generally indicates single type fluorescence quenching, which might represent either static or dynamic quenching. ${ }^{27}$ The Stern-Volmer plot was found to be linear for CHB-BSA system. The linear regression analysis of the plot yielded the value of the Stern-Volmer constant, $K_{S V}$ as $3.57 \times 10^{4} \mathrm{M}^{-1}$ (Table 1). This value of $K_{S V}$ was used to calculate the $k_{q}$ value (5.67 $\times 10^{12} \mathrm{M}^{-1} \mathrm{~s}^{-1}$, Table 1), which was found higher than the maximum dynamic quenching rate constant $\left(2.0 \times 10^{10}\right.$ $\left.\mathrm{M}^{-1} \mathrm{~s}^{-1}\right)$, reported for a number of quencher-fluorophore systems $^{27-29}$ and suggested complexation between $\mathrm{CHB}$ and $\mathrm{BSA}$.

CHB-BSA interaction was characterized by determining the binding parameters such as binding constant $(K)$ and number of binding sites $(n)$, which were obtained from the double log plot (Figure 3B). The $K_{a}$ value 

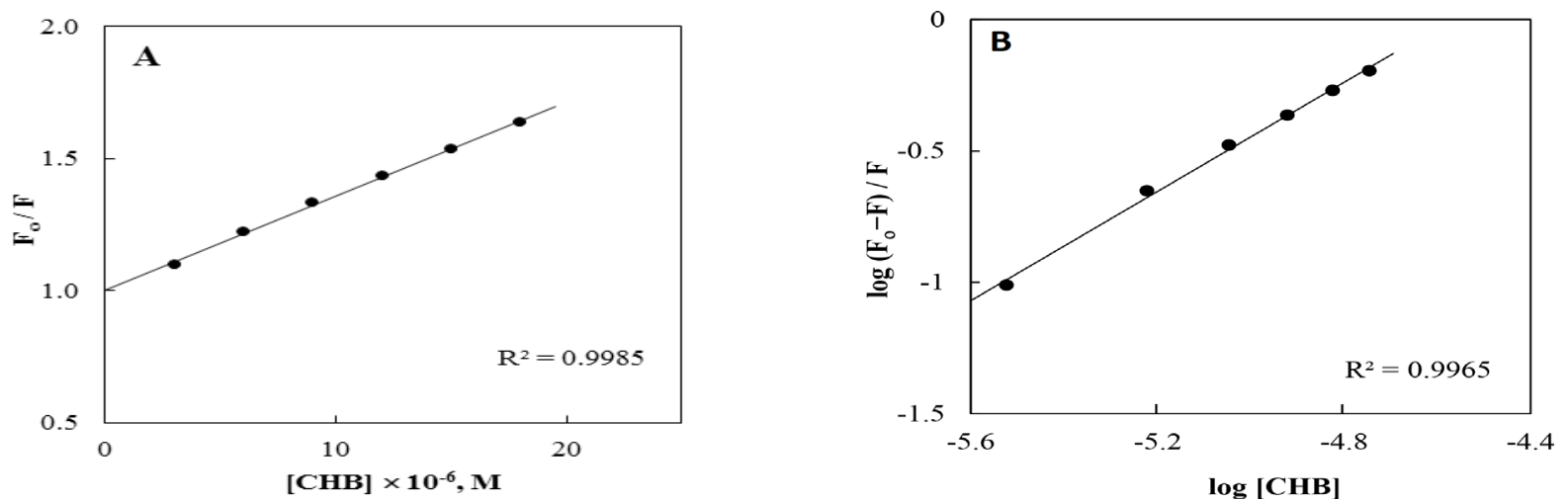

Figure 3: (A) Stern-Volmer plot and (B) Double logarithmic plot of $\log \left(F_{0}-F\right) / F$ against log [CHB] for the fluorescence quenching data, shown in Figure 2.

Table 1: Binding and thermodynamic parameters of the CHB-BSA interaction, studied at $25^{\circ} \mathrm{C}, \mathrm{pH} 7.0$.

\begin{tabular}{|c|c|}
\hline Parameter & Value \\
\hline$K_{S V}$ & $3.57 \times 10^{4} \mathrm{M}^{-1}$ \\
\hline$k_{q}$ & $5.67 \times 10^{12} \mathrm{M}^{-1} \mathrm{~s}^{-1}$ \\
\hline$K_{a}$ & $5.58 \times 10^{4} \mathrm{M}^{-1}$ \\
\hline$n$ & 1.0 \\
\hline$\Delta G$ & $-25.95 \mathrm{~kJ} \mathrm{~mol}^{-1}$ \\
\hline
\end{tabular}

was determined to be $5.58 \times 10^{4} \mathrm{M}^{-1}$ (Table 1), which indicated moderate binding affinity for CBH-BSA system. This value was similar to earlier reports for several ligand-BSA interactions. ${ }^{5,30}$ Moderate binding affinity is beneficial for the transportation of the drug through blood circulation, as it is easy to release the drug at the target sites from the blood stream. ${ }^{6,30}$ Value of $n=1.0$ suggested single binding site of $\mathrm{CHB}$ on BSA. Furthermore, the value of $\Delta G^{\circ}\left(-25.95 \mathrm{~kJ} \mathrm{~mol}^{-1}\right)$ for CHB-BSA interaction suggested that the binding process was spontaneous. ${ }^{31}$

\section{Molecular Docking Analysis}

Molecular docking simulation allowed the prediction of favourable binding interactions and orientation of $\mathrm{CHB}$ on the main hydrophobic cavities (Site I and Site II) of BSA. Evaluation of cluster analysis (Figure 4) indicated that a total of 4 and 21 multimember conformational clusters were generated for Site I and Site II of BSA, respectively. The highest populated cluster on Site I was comprised of 94 members with a mean binding energy of $-25.82 \mathrm{~kJ} \mathrm{~mol}^{-1}$. Meanwhile, the highest populated cluster on Site II had a mean binding energy of $-18.54 \mathrm{~kJ} \mathrm{~mol}^{-1}$ with 21 members. Moreover, the lowest binding energy calculated on Site I and Site II was $-27.99 \mathrm{~kJ} \mathrm{~mol}^{-1}$ and $-30.75 \mathrm{~kJ} \mathrm{~mol}^{-1}$, respectively. This result indicated that $\mathrm{CHB}$ had a binding preference for Site II since stronger energy was generated. Further inspection of the generated binding interactions

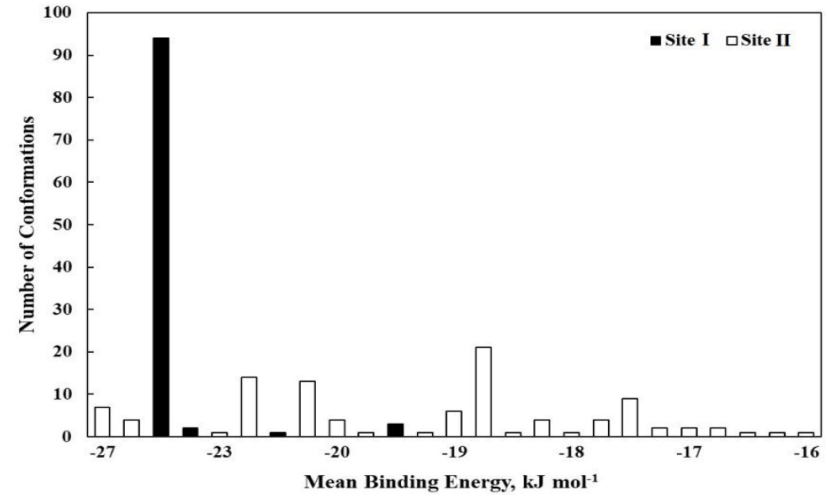

Figure 4: Cluster analysis of the molecular docking simulation of CHB binding to Site I (subdomain IIA) and Site II (subdomain IIIA) of BSA. A total of 100 runs were made for each biding site.

between $\mathrm{CHB}$ and BSA was made using the predicted model with the lowest binding energy as visualised in Figure 5. As can be seen from the figure, three hydrogen bonds were formed at Site II compared to two hydrogen bonds, formed at Site I in the complex (Table 2). The docked position of $\mathrm{CHB}$ on Site II was lined by 18 amino acid residues within $5 \AA$ distance: Leu-386, Ile-387, Asn-390, Cys-391, Phe-394, Phe-402, Leu-406, Arg-409, Tyr-410, Lys-413, Leu-429, Val-432, Gly-433, Cys-437, Thr-448, Leu-452, Arg-484 and Ser-488. Around $50 \%$ of these residues were hydrophobic in nature while remaining 50\% also contributed towards hydrophobicity of the binding site. Meanwhile, formation of two hydrogen bonds at Site I (Table 2) represented a weaker interaction between $\mathrm{CHB}$ and BSA. Overall, CHB appeared to form a more stable complex with BSA at Site II than Site I. In addition, both binding sites I and II of BSA were found to be surrounded by hydrophobic amino acid residues which might stabilize CHB-BSA complex through hydrophobic interactions (Figure 6). Thus, the molecular forces i.e., hydrogen bonds and hydrophobic forces are supposed to be the 
Table 2: Predicted hydrogen bonds formed between atoms of the BSA amino acid residues and CHB at

Site I and Site II, as obtained from docking evaluation.

\begin{tabular}{|c|c|c|c|}
\hline BSA binding site & BSA atom & CHB atom & Distance (A) \\
\hline $\begin{array}{c}\text { Site I } \\
\text { (subdomain IIA) }\end{array}$ & $\begin{array}{c}\text { Arg-198: } \\
\text { HH11 }\end{array}$ & 0 & 2.22 \\
\cline { 2 - 4 } & Arg-217: HE & O & 1.78 \\
\hline \multirow{3}{*}{$\begin{array}{c}\text { Site II } \\
\text { (subdomain IIIA) }\end{array}$} & $\begin{array}{c}\text { Asn-390: } \\
\text { HD22 }\end{array}$ & O & 1.70 \\
\cline { 2 - 4 } & Arg-409: HE & O & 1.78 \\
\cline { 2 - 4 } & $\begin{array}{c}\text { Arg-409: } \\
\text { HH21 }\end{array}$ & 0 & 2.13 \\
\hline
\end{tabular}

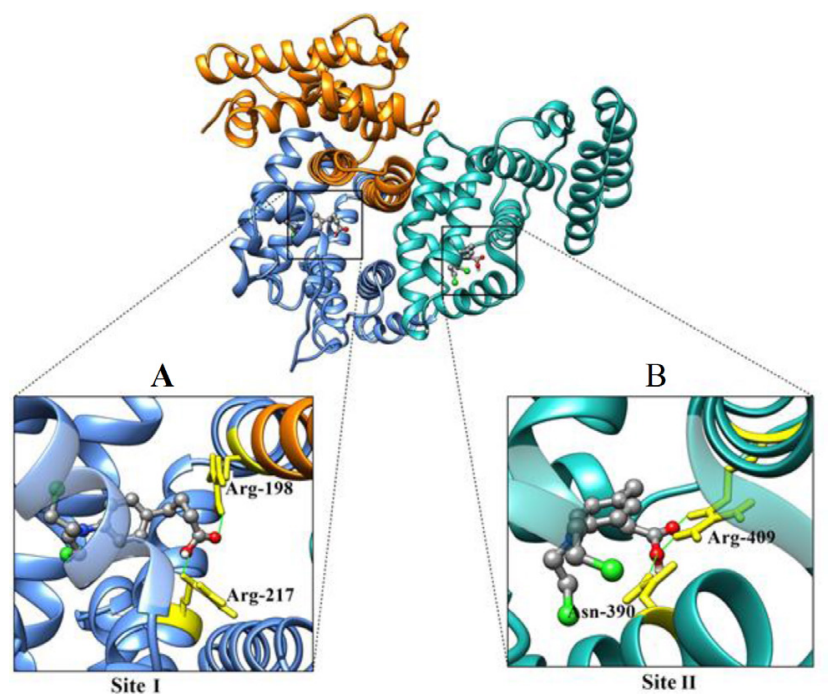

Figure 5: Predicted orientation of CHB (rendered in ball and stick) on (A) Site I and (B) Site II of BSA (PDB ID: 4F5S) based on the lowest binding energy. The three domains of BSA are coloured in orange (domain I), blue (domain II) and green (domain III). The zoomed-in image shows the hydrogen bonds (green lines), formed between the amino acid residues of BSA (rendered in yellow stick) and CHB at the binding site, located in the subdomain IIA (Site I) and IIIA (Site II), respectively.

major forces for stabilizing the CHB-BSA complex. These results were in accordance to the previously published reports, where the ligand binding has been shown to involve both hydrophobic interactions and hydrogen bonding. ${ }^{7,8,26,32}$

\section{CONCLUSION}

The results of CHB-BSA interaction study revealed moderate binding affinity between $\mathrm{CHB}$ and BSA and the complexation was found to be spontaneous. Interaction of $\mathrm{CHB}$ with BSA involved both hydrophobic interactions and hydrogen bonds. Besides, the preferred binding site for CHB was identified in subdomain IIIA which was Sudlow's Site II of BSA. Therefore, these results offer valuable information about the pharmacokinetics of $\mathrm{CHB}$ in mammalian circulation.

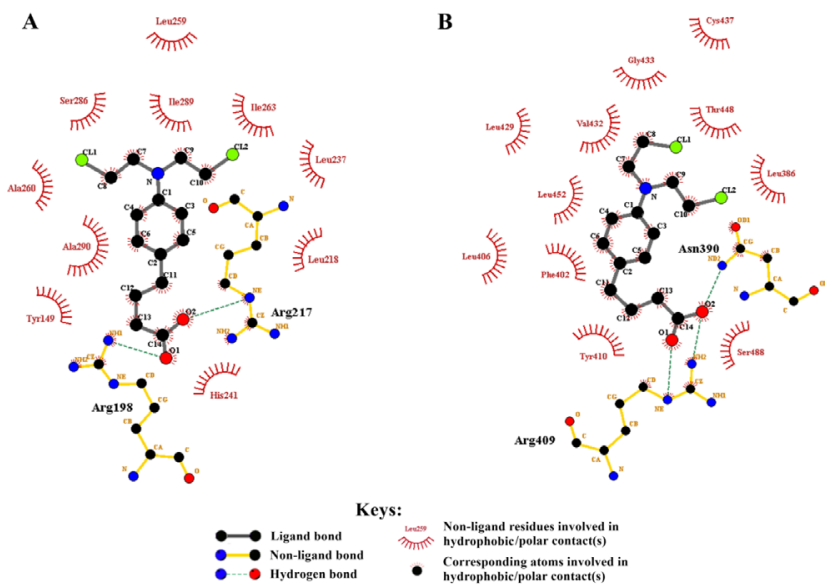

Figure 6: The ligand-protein interaction between $\mathrm{CHB}$ and BSA at Site I (A) and Site II (B) showing hydrophobic cavities of BSA using LigPlot+.

\section{ACKNOWLEDGEMENTS}

Financial support from the University of Malaya in the form of Fundamental Research Grant (FG025-17AFR) to S.T. is gratefully acknowledged. We thank the Dean, Faculty of Science and the Head, Institute of Biological Sciences, University of Malaya for providing necessary facilities.

\section{CONFLICT OF INTEREST}

The authors declare no conflict of interest.

\section{ABBREVIATIONS}

BSA: Bovine serum albumin; CHB: Chlorambucil; $\boldsymbol{K}_{\mathbf{s v}}$ : Stern-Volmer constant; $\boldsymbol{k}_{q}$ : Bimolecular quenching rate constant; $\boldsymbol{K}_{a}$ : Binding constant.

\section{REFERENCES}

1. Wohrer S, Raderer M, Kaufman H, Hejna M, Chott A, et al. Effective treatment of indolent non-Hodgkin's lymphomas with mitoxantrone, chlorambucil and prednisone. Onkologie. 2005;28(2):73-8.

2. Francisco AP, Perry MJ, Moreira R, Mendes E. Alkylating agents: Anticancer Therapeutics. John Wiley and Sons, Ltd. 2008;133-58.

3. Flarakos J, Morand KL, Vouros P. High-throughput solution-based medicinal library screening against human serum albumin. Anal Chem. 2005;77(5):1345-53.

4. Shahabadi N, Fili SM. Molecular modeling and multispectroscopic studies of the interaction of mesalamine with bovine serum albumin. Spectrochim Acta A Mol Biomol Spectrosc. 2014;118:422-9.

5. Sakhaei N, Halim AAA, Tayyab S. Warfarin binding to native and structurallyaltered human serum albumins. Indian J Pharm Educ Res. 2015;49(3):225-30.

6. Tunç S, Cetinkaya A, Duman O. Spectroscopic investigations of the interactions of tramadol hydrochloride and 5-azacytidine drugs with human serum albumin and human hemoglobin proteins. J Photochem Photobiol B. 2013;120:59-65.

7. Kabir MZ, Tee W, Mohamad SB, Alias Z, Tayyab S. Comprehensive insight into the binding of sunitinib, a multi-targeted anticancer drug to human serum albumin. Spectrochim Acta A Mol Biomol Spectrosc. 2017;181:254-63. 
8. Shiriskar SM, Agarwal N, Pissurlenkar RR, Ahmad B. Effects of 2-amino-8hydroxyquinoline interaction on the conformation of physiological isomers of human serum albumin. Eur Biophys J. 2015;44(4):193-205.

9. Peters T. Serum albumin. Adv Protein Chem. 1985;37:161-245.

10. Carter DD, Ho JX. Structure of serum albumin. Adv Protein Chem. 1994;45:153-203.

11. Huang BX, Kim HY, Dass C. Probing three-dimensional structure of bovine serum albumin by chemical cross-linking and mass spectrometry. J Am Soc Mass Spectr. 2004;15(8):1237-47.

12. Hirayama K, Akashi S, Furuya M, Fukuhara K. Rapid confirmation and revision of the primary structure of bovine serum albumin by ESIMS and Frit-FAB LC/MS. Biochem Biophys Res Commun. 1990;173(2):639-46.

13. Reynolds JA, Herbert S, Polet $\mathrm{H}$, Steinhardt J. The binding of divers detergent anions to bovine serum albumin. Biochemistry. 1967;6(3):937-47.

14. Lakowicz JR. Principles of Fluorescence Spectroscopy. $3^{\text {rd }}$ ed. New York: Springer. 2006.

15. Togashi DM, Ryder AG, Mc M, Dunne P, McManus J. Fluorescence study of bovine serum albumin and $\mathrm{Ti}$ and $\mathrm{Sn}$ oxide nanoparticles interactions. Proc SPIE. 2007;6628:66281K1-11.

16. Wang $Q$, Liu X, Su M, Shi Z, Sun H. Study on the interaction characteristics of cefamandole with bovine serum albumin by spectroscopic technique. Spectrochim Acta A Mol Biomol Spectrosc. 2015;136(Pt B):321-6.

17. Lee WQ, Kameel NIA, Mohamad S, Tayyab S. Comparison of pendimethalin binding properties of serum albumins from various mammalian species. Turk J Biochem. 2018. doi: https://doi.org/10.1515/tjb-2018-0031.

18. Morris GM, Huey R, Lindstrom W, Sanner MF, Belew RK, et al. Autodock4 and AutoDockTools4: automated docking with selective receptor flexibility. J Comput Chem. 2009;30(16):2785-91.

19. Halgren TA. Merck molecular force field. I. Basis, form, scope, parameterization and performance of MMFF94. J Comput Chem. 1996;17(5-6):490-519.

20. Hanwell MD, Curtis DE, Lonie DC, Vandermeersch T, Zurek E, Hutchison GR. Avogadro: An advanced semantic chemical editor, visualization and analysis platform. J Cheminform. 2012;4(1):1-17.

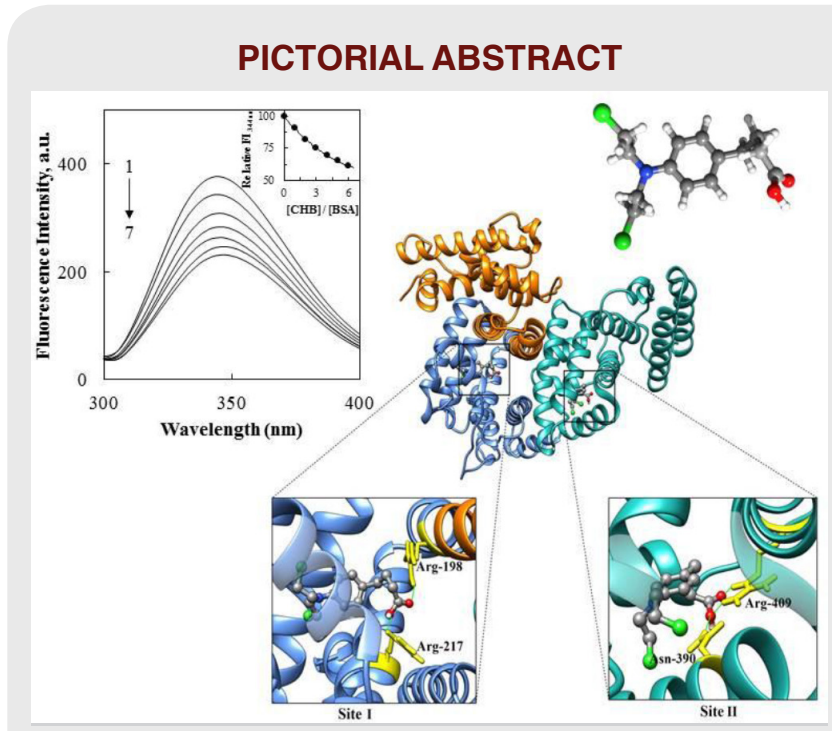

21. Pettersen EF, Goddard TD, Huang CC, Couch, GS, Greenblatt DM, et al. UCSF Chimera - A visualization system for exploratory research and analysis. J Comput Chem. 2004;25(13):1605-12.

22. Wallace AC, Laskowski RA, Thornton JM. LIGPLOT: A program to generate schematic diagrams of protein-ligand interactions. Protein Eng. 1995;8(2):127-34.

23. Guo X, Zhang L, Sun X, Han X, Guo C, Kang, P. Spectroscopic studies on the interaction between sodium ozagrel and bovine serum albumin. J Mol Struct. 2009;928(1-3):114-20.

24. Sulkowska A. Interaction of drugs with bovine and human serum albumin. J Mol Struct. 2002;614(1-3):227-32.

25. Kragh-Hansen U, Chuang VTG, Otagiri M. Practical aspects of the ligandbinding and enzymatic properties of human serum albumin. Biol Pharm Bull. 2002;25(6):695-704.

26. Kamtekar N, Pandey A, Agrawal N, Pissurlenkar RR, Borana M, Ahmad B. Interaction of multimicrobial synthetic inhibitor 1,2-bis(2-benzimidazolyl)-1,2ethanediol with serum albumin: spectroscopic and computational studies. PLoS One. 2013;8(1):e53499.

27. Paul BK, Ghosh N, Mukherjee S. Binding interaction of a prospective chemotherapeutic antibacterial drug with $\beta$-lactoglobulin: Results and challenges. Langmuir. 2014;30(20):5921-9.

28. Rabbani G, Baig MH, Jan AT, Ju Lee E, Khan MV, Zaman M, et al. Binding of erucic acid with human serum albumin using a spectroscopic and molecular docking study. Int J Biol Macromol. 2017;105(Pt 3):1572-80.

29. Ware WR. Oxygen quenching of fluorescence in solution: An experimental study of the diffusion process. J Phys Chem. 1962;66(3):455-8.

30. Wang N, Ye L, Zhao BQ, Yu JX. Spectroscopic studies on the interaction of efonidipine with bovine serum albumin. Braz J Med Biol Res. 2008;41(7):589-95.

31. Kong D, Qin C, Fan P, Li, B, Wang J. Spectroscopic studies on interaction of BSA and $\mathrm{Eu}$ (III) complexes with $\mathrm{H}_{5}$ ph-dtpa and $\mathrm{H}_{5}$ dtpa ligands. Spectrochim Acta A Mol Biomol Spectrosc. 2015;140:372-81.

32. Ratnaparkhi A, Muthu SA, Shiriskar SM, Pissurlenkar RR, Choudhary S, Ahmad B. Effects of hesperidin, a flavanone glycoside interaction on the conformation, stability, and aggregation of lysozyme: Multispectroscopic and molecular dynamic simulation studies?. J Biomol Struct Dyn. 2015;33(9):1866-79.

\section{SUMMARY}

Chlorambucil, an anticancer drug binds to serum albumin with moderate binding affinity and has binding preference for Site II in the protein.

\section{ABOUT AUTHORS}

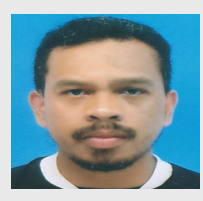

Dr. Saharuddin bin Mohamad, Senior Lecturer, Bioinformatics Programme, Institute of Biological Sciences, Faculty of Science, University of Malaya, Kuala Lumpur, Malaysia.

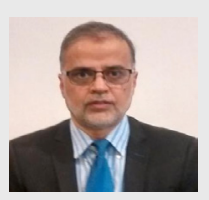

Dr. Saad Tayyab, Professor, Biochemistry Programme, Institute of Biological Sciences, Faculty of Science, University of Malaya, Kuala Lumpur, Malaysia.

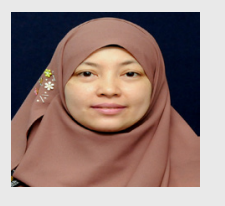

Dr. Adyani Azizah Abd Halim, Senior Lecturer, Department of Oral and Craniofacial Sciences, Faculty of Dentistry, University of Malaya, Kuala Lumpur, Malaysia.

Cite this article: Saufi ANM, Ridzwan NFW, Mohamad SB, Tayyab S, Halim AAA. Fluorometric and Docking Analysis of the Complex Formation between an Anti-Cancer Drug, Chlorambucil and Bovine Serum Albumin. Indian $\mathrm{J}$ of Pharmaceutical Education and Research. 2019;53(4):682-7. 